\title{
El proceso de escritura de los Comentarios reales y la historia natural
}

\author{
Fermín DEL PINO-DÍAZ \\ Centro de Ciencias Humanas y Sociales (CSIC) \\ fermindelpino@gmail.com
}

\begin{abstract}
RESUMEN
El artículo se propone una revisión y reflexión en torno a los Comentarios reales del Inca Garcilaso, teniendo en cuenta su relación con historias naturales sobre América que se redactaron antes que su texto, en las que se apoyó, haciendo especial hincapié en la crónica de José de Acosta.
\end{abstract}

Palabras clave: Comentarios reales, Inca Garcilaso, historia natural.

The process of writing of the Comentarios reales and the natural history

\begin{abstract}
The article proposes a review and reflection itself concerning the of the Inca Garcilaso, bearing his relation in mind with natural histories on America that was written before that his text, on that it rested, doing special support in Jose de Acosta's chronicle.
\end{abstract}

Key words: Comentarios reales, Inca Garcilaso, natural history.

Para obtener la licencia final de impresión de sus Comentarios reales, el Inca Garcilaso hizo entregar en 1604 'siete libros en un tomo" al Santo Oficio de Lisboa (según se declara en 1607, en los Preliminares), pero la obra no saldrá hasta finales de 1609: entonces incluye ya dos libros más, que se supone agregó el autor en estos dos años de espera. Es posible deducir ahora que la historia natural, introducida finalmente por el autor en los libros VIII y IX, se agregó posteriormente a 1604, y hay rastro de esas fechas de composición en estos libros. Aunque es verdad que en el capítulo "De las hortalizas y hierbas, de la grandeza dellas" se citan fechas anteriores como data de su historia natural (IX, 29: "el año de 1595, por el mes de mayo... iba en este paso de nuestra historia").

De hecho, inicialmente no le interesaba al Inca ocuparse de la historia natural. Aunque al principio de la obra (en sus dos primeros capítulos) asoman algunas materias naturalistas como en esbozo ("Si hay muchos mundos", "Si hay antípodas", etc.), enseguida se sumerge el autor en los temas históricos y lingüísticos del Perú, como la materia en que halla cómodo. Por ello, ya desde el 
cap. 2 del libro I confiesa el autor su mayor interés por la historia moral que por la natural:

decir de las mieses, legumbres y frutas, tan diferentes de las de acá,... así en los animales mansos y bravos... como en los hombres... en cosas tan inciertas es perdido el trabajo que se gasta en quererlas saber: las dejaré porque tengo menos suficiencia que otro para inquirirlas. Solamente trataré del origen de los reyes incas y de la sucesión dellos, sus conquistas, leyes y gobierno en paz y en guerra (cursivas mías).

Afortunadamente (como también tuvo múltiples experiencias en cosas cotidianas de interés material) el autor agregó finalmente en los libros VIII y IX una treintena de capítulos sobre las plantas y animales de ambos tipos, tradicionales y nuevos: "[los] que había y que no había en aquel imperio, antes que los españoles fueran a él" (17 totales en el libro VIII, y 16 en el IX). Como hace en el resto de la obra, estos capítulos fueron intercalados entre medias de la historia de los monarcas peruanos finales, Huayna Cápac y sus dos hijos, sucesores compitiendo en una guerra civil a muerte. El carácter interpolado de estas 'historias reales' lo reconoce el propio autor, cada vez que interrumpe el relato etnográfico (tema pensado originalmente), y lo excusa repetidamente como un descanso o alivio intelectual para el lector: de hecho, el descanso se requiere tras leer los monótonos sucesos de cada Inca, todos cortados por el mismo patrón: el cuidado paternal de sus súbditos, propios y ajenos. Los traductores franceses de la obra en 1744 se creyeron obligados a ampliar las noticias naturalistas del Inca Garcilaso, con las noticias recientes adquiridas por La Condamine en notas y paréntesis numerosos; pero además hicieron otro cambio, menos mencionado por los analistas: seleccionar los numerosos capítulos dispersos en la obra sobre el gobierno incaico, y formar así el tomo I, precedido de un elogioso prólogo admirativo de las bondades de un gobierno pagano, oportuno modelo ante la decadencia de los reinos cristianos del s. XVIII: una especie de 'Utopía' de Tomas Moro rediviva. ${ }^{1}$

La obra general de historia del Perú que se propone acometer le lleva muchos años desarrollarla (1586-1604 para la primera parte), y evidentemente sufre muchas alteraciones en su contenido y composición. Aparte del agregado naturalista, el autor promete al fin de la obra de 1609 entrar "en el libro décimo, a tratar de las heroicas e increíbles hazañas de los españoles que ganaron aquel imperio": materia que no saldrá a la luz mientras vive, aunque sí la puede concluir. Saldrá esta segunda parte como obra póstuma, publicada en Córdoba, porque se fue engrosando

${ }^{1}$ Ver Fernanda Macchi, Incas ilustrados: reconstrucciones imperiales en la segunda mitad del siglo XVIII, Madrid, Iberoamericana Editorial, 2009 y Neil Safier, La medición del Nuevo Mundo. La Ciencia de la Ilustración y América del Sur. Madrid, Marcial Pons, 2016, original inglés de 2008. 
poco a poco hasta llegar a ocho libros (no uno solo, como anunció en 1609), con una extensión total mayor que la primera. ${ }^{2}$ Por citas tempranas de sus primeros proyectos antes de 1590 ya era sabido (en las dos dedicatorias a Felipe II de su traducción de León hebreo, luego repetidas en el prólogo de su Florida, 1605) que el autor proyectaba escribir sobre las antigüedades peruanas, primeramente de todo; luego el proyecto se iría ampliando hasta tratar detenidamente sobre la historia política incaica y la historia natural. Es sólo al final del todo que se interesa sobre la conquista española del Perú.

Hoy vamos a restringirnos a los fragmentos naturalistas añadidos, en los primeros años del s. XVII, en la primera parte de los Comentarios Reales. Son muy interesantes estos capítulos para detectar el proceso interno de composición, a lo largo de toda la obra en general, donde trata de comunicarnos -al mismo tiempotanto su experiencia personal como informes detallados sobre la materia, nuevamente ofrecida: a su insistencia constante en transmitirnos con la historia natural solamente sus propias vivencias, que es el tono subyacente de la obra, se suma siempre su dependencia de informes ajenos, escritos o recibidos de viva voz: en efecto, tras dejarnos su propia versión del país materno abandonado hacía 40 años, en un relato siempre ameno, variado y contagioso (que busca nuestra complicidad de lector), se unen otra vez relatos diversos de cronistas hispanos o mestizos (especialmente de dos jesuitas respetables, el peruano Blas Valera y el castellano José de Acosta), así como numerosas anécdotas y sucedidos: que suele llamar 'cuentos', y que expresan ingenuamente tanto la curiosidad de lo nuevo como la melancolía respecto de lo viejo que ejerce el mundo natural a los ojos de cada uno de los dos actores colectivos (indios o españoles). Los indios se sorprenden y asustan de las cosas desconocidas del Viejo Mundo aportadas por españoles (caballos, uvas, melones...), y los españoles se adaptan a los nuevos animales y flora, pero añoran la ausencia de lo viejo conocido y se gastan sus enormes ahorros por recuperarlo.

Me parece también que estos 33 capítulos, que componen por sí mismos la extensión de un libro entero -incluso de tamaño abultado para el promedio de unos 25 capítulos, que tiene cada uno de los nueve libros (menos el V y IX)- son una excelente muestra de 'interculturalidad', tema que se examina particularmente en esta obra y ha sido objeto de diversos congresos dedicados al Inca. ${ }^{3}$ No por tratarse de cosas 'objetivas' y materiales descritas con la fruición sensual esperable de un

${ }^{2}$ En la reciente edición de Araníbar, la $1^{\mathrm{a}}$ parte ocupa 549 pp., y la 2a 774 (más de un tercio de exceso narrativo). Ver Inca Garcilaso de la Vega, Obras completas, 3 tomos, Lima, Ministerio de Relaciones Exteriores del Perú, 2015.

3 La primera versión de este ensayo fue presentada en Córdoba, en el congreso internacional coordinado por María Ángeles Hermosilla, "El Inca Garcilaso y su proyección en la interculturalidad de hoy", Junio de 2016 
exilado melancólico -o incluso con la minuciosidad de un 'viajero impertinente', género que pondrán de moda en el s. XIX los ingleses, pero que se engendra ya por entonces entre autores renacentistas, y al que contribuye el Inca a lo largo de su viaje de venida a España en 1560) -no por ello, digo, dejan de aparecer problemas de inter-subjetividad y, sobre todo de intertextualidad. Creo que en este triple proceso de mestizaje (físico, emocional y también textual) es donde radica la maestría del primer escritor del Nuevo Mundo, acogido en Córdoba y Montilla por su familia y sus nuevos amigos andaluces.

\section{La historia en la tradición cronística previa al inca Garcilaso}

Es evidente que el Inca comienza escribiendo de manera tradicional su "historia del Perú" (así le llama en su correspondencia reiteradamente), al modo de los cronistas entonces más conocidos: Pedro de Cieza, y Agustín de Zárate, pero especialmente de López de Gómara y del jesuita Acosta, seguramente los dos modelos finalmente más determinantes para él. Ellos dos le daban datos preciosos y autorizados, como otros cronistas, pero sobre todo empleaban un 'estilo' intelectual dentro de un corpus de historiografía humanista, modelo elegido por el autor. Garcilaso inca no estuvo de acuerdo en todo con sus modelos, lo que se acomodaba perfectamente al orgulloso patrón humanista. Con Gómara, el primero de ellos, se enfrentó ya desde 1563, tras la contestación negativa a sus peticiones de premio de parte del miembro del Consejo Real de Indias, Lope Gacía de Castro (que no era un funcionario ordinario, pues será enseguida enviado al Perú como visitador del virrey Conde de Nieva, y quedará por cinco años como presidente de la Audiencia de Lima, desde septiembre 64 a noviembre del 69). Eso determinó probablemente que el regreso a su tierra del joven Suárez de Figueroa, proyectado en 1563, se cambiase por un traslado definitivo a la Andalucía de su familia paterna, y que cambiase su nombre a Garcilaso de la Vega (como su padre y como su tío abuelo, el gran poeta castellano).

Afortunadamente conservamos la huella de su lectura de Gómara (en un ejemplar del libro profusamente anotado, ahora en la Biblioteca Nacional de Lima, que posiblemente sea el único conservado de su amplia biblioteca). ${ }^{4}$ Es probable

\footnotetext{
${ }^{4}$ Ha sido objeto de una edición facsímil, al menos. Francisco López de Gómara, Historia general de las Indias, ed. facs., Comisión Nacional del Quinto Centenario del Descubrimiento de América-Encuentro de Dos Mundos, Lima, 1993. Ver un estudio proyectado para una segunda edición en José L. Rivarola: "El taller del Inca Garcilaso. Sobre las anotaciones manuscritas en la Historia general de las Indias de F. López de Gómara y su importancia en la composición de los Comentarios Reales", Revista de Filología Española, 75 (1995), 57-84. Ídem, "Para la génesis de los Comentarios Reales. Edición y comentario de las apostillas del Inca Garcilaso (y otros) a la Historia General de las Indias de F. López de Gómara", Nueva Revista de Filología Hispánica, L (2002), núm. 1, 59-139.
} 
que fuera en principio el propio ejemplar del capitán Gonzalo Silvestre donde comenzó a anotar y releer detenidamente la crónica de Gómara. Silvestre, hombre experimentado en el Nuevo Mundo tanto en la zona peruana como en la norteamericana de la Florida, luego principal informante cordobés del inca, nos dejó asimismo una relación breve de la Florida, recientemente editada por el finado Miguel Matirorena. ${ }^{5}$ Parece que pudiera ser Silvestre el informante -y tal vez autorde la crítica a Gómara que le hiciera en Valladolid un conquistador anónimo, apud Garcilaso, por hablar mal de Gonzalo Pizarro y su mariscal Carvajal, según John Grier Varner. ${ }^{6}$

En el fondo, el cronista Gómara no es un autor contrario al capitán Garcilaso: ofrece una opinión no del todo negativa de su padre, a quien describe a veces como amigo de Gonzalo Pizarro, pero asimismo crítico con él y partidario del rey. Es el Palentino (Diego Fernández, cronista del virrey marqués de Cañete) quien decribe la 'traición' real de su padre de un modo más crudo (exagerando el gesto de la cesión de su caballo al amigo Gonzalo en ocasión oportuna, porque había perdido el suyo en plena batalla de Huarina); pero, de cualquier forma que se vea su relación estrecha con el rebelde Pizarro, es evidente para cualquier lector atento que en la batalla de Huarina, su padre estuvo del lado de Gonzalo y contra las tropas reales, y que volvió triunfante a Cuzco, mientras su propio hermano Juan de Vargas murió por heridas recibidas en la misma batalla, del lado realista. Todavía tenemos conservado en los Comentarios el recuerdo gozoso de su hijo pequeño (con 8 años) recibiendo en Cuzco al ejército rebelde triunfante, a hombros de sus servidores indios.

Aunque el padre se pasara finalmente, en la batalla de Xaquixahuana, al bando del visitador y regente real Lagasca, éste no se fiaba totalmente de él, si bien prefiriese luego premiarle públicamente para obtener su adhesión al partido real (contrariando a muchos leales a la Corona): por eso, tal vez, no quiso autorizarle en 1549 a coronar su vida con una boda con la 'esposa' incaica que gobernó su casa durante 10 años (1538-1548), la palla Chimpu Ocllo, bautizada Isabel Suárez. Su intimidad con las familias reales incaicas le hacía un posible líder del poder criollo español en Cuzco: puede verse esta intimidad en su papel de padrino de bautizo del Inca Paullu en 1543, así como de su hermano Titu Auqui (1609, Libro VI, capítulo 2), y que lo pudo ser en 1558 del inca Sairy Tupac, de no haber estado ya enfermo de muerte (1617, VIII, 11). De todo ello se vanagloriaba su hijo: su padre precisamente, no su madre, es quien permite al joven Gomes Suárez de Figueroa llamarse al fin 'inca' (pues, no lo olvidemos, él nos insiste reiteradamente en que el

${ }^{5}$ La Florida. Facsímil de un nuevo manuscrito, Editorial Universidad Ricardo Palma, Lima, 2015.

${ }^{6}$ El Inca. Life ant times of Garcilaso de la Vega. Austin and London: University of Texas Pres, 1968, p. 222. 
deseado linaje incaico se hereda sólo por vía paterna). Si no fue de ningún modo aceptable para la Corona la boda de Gonzalo Pizarro con su sobrina de sangre real (Francisca de Pizarro, heredera de mucho dinero y descendiente del noble linaje incaico, que concluiría en España de esposa de su tío Hernando Pizarro), menos aún estaba dispuesto el enviado real, celoso de la lealtad de la nobleza indiana, a permitir que lo hiciera un personaje noble como Garcilaso de la Vega, de ascendencia Mendoza. Aunque encerrado en el castillo de la Mota durante 23 años en castigo por la muerte de su rival Almagro, Hernando Pizarro (por estar casado con Francisca Pizarro) no dejó de llevar una vida palaciega, ni de ser uno de los hombres más ricos de la monarquía hispana. Porque esa boda de Garcilaso e Isabel Suárez le hubiera consagrado como una poderosa instancia autónoma, a los ojos de la Corona. ${ }^{7}$

Es evidente que el Consejo de Indias tenía opiniones propias sobre su padre el capitán Garcilaso de la Vega (a través de los informes de Lagasca, D. Antonio de Mendoza y posteriores del virrey marqués de Cañete 1556/1561, desconfiado de la lealtad del capitán Garcilaso y Vargas) y sabía de su peso como hombre formador de opiniones nobiliarias, y como líder entre los resistentes a las Leyes Nuevas. La cesión momentánea del emperador en 1542 a las presiones lascasianas (criticando la conquista, limitando las encomiendas a dos vidas -la del conquistador titular y un heredero-, y prohibiendo las encomiendas de servicio, no las de tributo) no había agradado nada al bando conquistador, que creyó haber ganado un imperio espléndido a su costa solamente, no de la Corona (como solían establecer las capitulaciones que consagraban los títulos de cada conquistador), y sin posterior beneficio propio de ningún tipo. Los viejos conquistadores, cansados tras el esfuerzo inicial, ni siquiera pudieron gozar de su propio matrimonio final, y sus viudas enriquecidas caían en brazos de nuevos esposos advenedizos: ese fue el caso del propio padre del inca, y del mismo Hernando Pizarro.

De hecho, toda la Segunda parte de los Comentarios reales (póstumamente llamada Historia General del Perú) es una defensa sostenida del bando pizarrista. Es la postura heroica de un grupo de nuevos nobles cristianos (ennoblecidos justamente en la conquista, como derivado de su súbito enriquecimiento) que se cree digno de administrar las Indias en nombre de los incas vencidos, puesto que fueron ellos quienes ganaron la batalla a su enemigo Atahuallpa, y eran bienquistos de los incas del bando de Huáscar (Paulo Inca, Sayri Tupac...). El encumbramiento honorífico de su padre, reconocido por las familias incaicas supervivientes a la matanza generalizada de Atahualpa (sobre todo del linaje de Huáscar, incluyendo parientes cercanos, servidores e incluso hijos todavía por nacer, asesinados en el

${ }^{7} \mathrm{He}$ abundado antes en esta argumentación en "Cuzco y Roma, peruanos y andaluces en la obra del Inca Garcilaso”, Anthropologica, Lima, año XXIX, n 29, diciembre de 2011, pp. 7-30. 
vientre de sus madres), sería luego reconocido también por la administración española, nombrándole corregidor del Cuzco en el período 1554-56, poco antes del respetado Polo Ondegardo (1558-60). Fue precisamente el licenciado Polo quien le despidió en el Cuzco como un viejo conocido, a la muerte de su padre, mostrándole en vivo las momias de los incas reinantes, recuperadas el año anterior por él con la colaboración nativa. Y Agustín de Zárate, que no acusa a su padre pero alaba a los incas, también compartiría el bando pizarrista (po lo que padeció cárcel igualmente) junto con su sobrino Polo de Ondegardo, ambos prestigiosos testigos pesenciales.

Gómara, como se sabe, es el primer cronista que ordena su historia indiana en términos geográficos (parte antillana, peruana y mexicana), de un modo completo que pudo mostrar al público (de hecho, su detenida descripción del Perú precede claramente a la de México., siendo la parte sustancial del primer tomo). Fernández de Oviedo no pudo dar a conocer ese panorama global, aunque lo hizo, pues sólo se publica entonces un tercio de su obra, la parte que afecta a las Antillas predominantemente; y el cronista real Antonio de Herrera ni siquiera puede mostrar este orden geográfico claramente en medio de sus minuciosos relatos cronológicos, en forma de décadas. Tampoco publicó entonces su historia completa el joven Cieza de León (por lo que tampoco pudo acceder el Inca a ver la segunda parte de su obra, sobre el Señorío de los Incas), aunque la primera influye mucho en el Inca, si bien carece propiamente de historia natural. Zárate no dedica tampoco espacio a la historia natural sino a la historia incaica, dejando este tema material a su coetáneo Gómara, aunque fuera informado solamente a distancia, sin viajar a las Indias.

El 'cronista real' López de Gómara, ${ }^{8}$ dedicaba parte importante de su Historia indiana a la vida natural y social, y no solamente a las guerras y a la historia política incaica o mexica. De algunos capítulos naturalistas iniciales de Gómara ('El mundo es uno y no muchos', 'Que el mundo es redondo', 'Que hay antípodes', 'De los cocuyo y niguas', 'Del pez que llaman manatí', 'De las vacas corcovadas, 'del pan de los indios', 'del color de los indios'...) ha tomado el Inca ejemplo naturalista. Por tanto, la obra de Gómara es un referente inexcusable para el Inca: lo cual queda reforzado además por el carácter refinado de su prosa renacentista, breve y

${ }^{8}$ Que lo fue al fin, tras pretenderlo mucho tiempo, y nunca lo fue de Hernán Cortés, como ahora se sabe tras la tesis doctoral de Nora Edith Jiménez: Francisco López de Gómara. Escribir historias en tiempos de Carlos $V$, Zamora (México), Colegio de Michoacán e INAH, 2001. Ver asimismo sobre Gómara y Cortés, Juan Miralles Ostos, “Gómara, ¿Capellán de Cortés?”, Boletín de la Real Academia de la Historia, T. CCVCuaderno II, Madrid, mayo-agosto 2009, pp. 165-175. Asimismo María del Carmen Martínez Martínez, "Francisco López de Gómara y Hernán Cortés: nuevos testimonios de la relación del cronista con los marqueses del Valle de Oaxaca", Anuario de Estudios Americanos, 67, 1 (2010), enero-junio, 267-302, Sevilla (España), 
sentenciosa, pero no exenta de opiniones e informaciones críticas sobre el comportamiento español, incómodas ciertamente para los conquistadores. Incluso resultó ser finalmente censurado oficialmente por su libertad de palabra, incómoda para la monarquía, que decretó la recogida de los ejemplares editados en el reino de Castilla (aunque la obra continuara editándose en Zaragoza, y fuera de España, tanto en castellano como en traducciones). Su influencia llegó a muchas partes, incluyendo al refinado alcalde de Burdeos, Michel de Montaigne, que se hace eco de su admiración al mundo indiano (natural y moral), y de su desnuda crítica a los conquistadores del oro americano.

Pero yo creo que la fuente que finalmente 'pone en marcha' el proyecto del inca es la obra el P. Acosta, que pasa por su propia Montilla en 1589, visitando por orden del P. General Acquaviva los colegios jesuitas andaluces; y que publica su conocida historia indiana en la vecina Sevilla (1590). Poco después, durante su visita del mismo tipo a la provincia aragonesa jesuita, contratará su segunda edición en Barcelona (1591, en formato menor y otra dedicatoria). El año 90 es la fecha que reiteradamente señala el Inca en sus Comentarios como el inicio de su epistolario con familiares y conocidos peruanos para confirmar detalles de su indagación histórica. Ambos, Acosta y el Inca, son personajes igualmente curiosos que se interesarán detenidamente por cada una de las novedades naturales del Nuevo Mundo: ambos toman apuntes para avivar por largo tiempo su memoria del pasado, para lo cual se informan de diversos residentes en cada enclave, consultan cosas de mar a pilotos bien informados, y toman nota sucesiva de los precios de cada mercancía y nuevo fruto. Sobre Acosta como fuente relevante de los capítulos naturalistas de Garcilaso ya trató autorizadamente Aurelio Miró Quesada, en su obra maestra. ${ }^{9}$

La de Acosta es la obra en quien el Inca depositará más su confianza: es un jesuita que da a los incas un papel providencial, debido a sus avances culturales (la lengua común, las vías romanas a lo largo del imperio, las pobladas ciudades, la autoridad indiscutida, el justo y previsor reparto económico...). Por encima de todo ello, el jesuita castellano y el caballero inca admiran la cultura de la Antigüedad, ponen a Roma como modelo del destino providencial de los Incas, evitando así hablar a la luz pública de los moriscos y judíos que pueblan aún España. Detrás de toda esa cuidada estrategia valorativa, que parece oficial, se les puede finalmente descubrir como 'personajes marginados', como sujetos excepcionales en su propia sociedad. La Iglesia es el refugio seguro de gran parte de estos notables 'conversos' y 'mestizos', especialmente frecuentes en Andalucía: véase la tesis esclarecedora y

9 El Inca Garcilaso y otros ensayos garcilasistas. Madrid, Instituto de Cultura Hispánica, 1971, pp. 172-176. 
coincidente del historiador jesuita Francisco de Borja Medina. ${ }^{10}$ Está claro que fue en Andalucía donde abundaban principalmente los candidatos de ascendencia judía aspirantes a ocupar plaza relevante en el interior de las órdenes religiosas (siendo los jesuitas los únicos que los aceptaban, porque S. Ignacio rechazaba frontalmente aplicar entre cristianos el estatuto de limpieza de sangre). Esta actitud aperturista de los jesuitas fue sólo interrumpida en 1593, precisamente contra el P. Acosta y los rebeldes memorialistas castellanos, de supuesta ascendencia conversa.

Tiene también mucho que ver con la desconfianza italiana ante el predominio castellano dentro de la Compañía de Jesús: a ello atribuye el P. Borja la excepcional atención y tolerancia concedida en Andalucía al desterrado jesuita mestizo Blas Valera, procedente del Perú (contra la orden expresa del General Acquaviva de no dejarle confesar ni predicar a los fieles), por lo cual no es extraño que no le hagan llegar a él los restos sobrevivientes de su historia incaica, redactada en latín: razón por la que el jesuita P. Maldonado la depositará en las manos del inca Garcilaso, en Córdoba.

Como decimos, es evidente el papel modélico del jesuita Acosta para el inca, que reproduce varias veces sus ideas, a veces con sus propios términos, aunque hay otras veces en que, a fuerza de mirar su modelo, Garcilaso corrige puntillosamente al jesuita (otoroncos como tigres, y no osos; 'labrar', y no 'sacar' perlas, etc.), para terminar reconociendo su autoridad en materia de historia natural: "Hasta aquí es del padre Acosta, cuya autoridad esfuerza mi ánimo para que, sin temor, diga la gran fertilidad que aquella tierra mostró a los principios con las frutas de España, que salieron espantables e increíbles" (VIII:29). Le llega a citar 17 veces, varias literalmente, en el total de 33 caps. de los libros VIII y XIX (es decir, más de una vez cada dos capítulos). En esta materia naturalista, ambos tomaban nota sistemática del comercio y precios de todo tipo de productos, mostrando los paralelismos biográficos de un hijo de conversos castellanos y un mestizo peruano, administrador de fincas. Pero, sobre la mera curiosidad sentida por el jesuita ante el

10 «Blas Valera y la dialéctica "exclusión-integración del otro"», Archivum Historicum Societatis Iesu, LXVIII-136 (julio-diciembre 1999), pp. 229-267. Es autor de otros trabajos anteriores sobre los marginados entre los jesuitas: «La Compañía de Jesús y la minoría morisca (1545-1614)», Archivum Historicum Societatis Iesu, LVII-113 (enero-junio 1988), pp. 3-136; "Ignacio de Loyola y la 'limpieza de sangre"”, en Ignacio de Loyola y su tiempo. Congreso Internacional de Historia, Bilbao 1991, pp. 579-616. He tratado de la relación entre Acosta y Garcilaso en ¿Dignidad cultural o proto-identidad cristiana de lo inca? Acerca del sentido preferente de los 'comentarios' garcilasianos al P. Acosta", en José A. Mazzotti (ed.), Renacimiento mestizo: los 400 años de los Comentarios reales. Madrid: Iberoamericana, 2010, pp. 51-77. Asimismo en "Mestizos americanos y conversos hispanos ¿posibles aliados?”, en Carmen de Mora, Guillermo Serés y Mercedes Serna (Editores), Humanismo, mestizaje y escritura en los Comentarios reales. Madrid/Frankfurt: VeruertIberoamericana, Col. Parecos y australes, nº 8, 2010, pp. 275-293. 
mundo natural peruano, al mestizo cordobés le preocupan mucho los negocios que pueden hacerse intercambiando productos naturales de uno y otro sitio: con caballos americanos en España, y con algunas plantas europeas en el Nuevo Mundo.

\section{Sobre su autoridad como glosador}

Es evidente la dependencia del Inca respecto de fuentes ajenas en su información histórica peruana, parte tomada tempranamente en el mismo Nuevo Mundo y parte después en la propia España. El autor no se priva de citarlas, cuando van en su favor, e incluso cuando van en contra: por ejemplo, numerosos testimonios del P. Acosta que no coinciden con su interpretación de los incas (su monoteísmo con Pachacamac, su ausencia de sacrificios humanos, el reparto entre guerreros victoriosos de las acllas sagradas, la crueldad de la guerra incaica contra otros pueblos, etc.) se toman para rebatirlos: pero sin mencionar al autor en esos casos, para no disminuir la autoridad ya concedida. Podríamos contarlas, con ayuda de la edición de Araníbar (que se toma la molestia de ofrecer las citas de cada autor con sangrado de margen en 1991-95, y con letra cursiva en 2016, aparte de anotaciones detalladas en su Glosario), pero ahora solamente queremos advertir una cosa de naturaleza metodológica, a este respecto: que el propósito constante -en cierto modo obsesivo- de mostrarse como autoridad testimonial le impide a veces mencionar una fuente colonial, cuyo uso es evidente a lo largo de la obra. Me refiero al Arte y Vocabulario en la Lengua general del Perú (Lima, 1586), editado por el III concilio limense, bajo el control del P. Acosta y la colaboración de misioneros lingüistas, especialmente jesuitas.

Si se examinan los nuevos hábitos de escritura quechua del Inca (muy rigurosos, pero todos derivados de seguir la norma de la lengua cuzqueña), todos se atienen perfectamente al manual del concilio limense. Sin atreverse del todo a sostener esa dependencia, el profesor Cerrón Palomino lo acaba sugeriendo en su reciente libro, del que me hizo donación reciente mi buen amigo José A. Mazzotti. ${ }^{11}$ El libro recoge ocho artículos que han salido a la luz en los años 90, donde se ofrecía una nueva interpretación de la autoridad lingüística del inca, moderadamente crítica debido en primer lugar a la larga ausencia del Perú (que el propio autor reconoce meridianamente, incluso en los capítulos de historia natural: particularmente en el libro VIII, como veremos), y seguidamente debido a su empeño en seguir la norma cuzqueña, como única legitimada y no bárbara. Eso no merma la fiabilidad autorial del autor como quechuista, sino que revalida su afirmación inicial de que no nos ofrece tanto una novedad como una 'interpretación glosada' de noticias ajenas, de superior calidad. A pesar del olvido propio de la lengua runasimi a causa de su lejanía geográfica, el inca puede manejar perfectamente un diccionario quechua,

11 Tras las huellas del inca Garcilaso. El lenguaje como hermenéutica en la comprensión del pasado, Ed. Revista de crítica literaria latinoamericana (Boston), 2013. 
sabe ofrecer su pronunciación correcta, y sabe la pertenencia o no de un vocablo al acervo propio (caso de la gallina como guallpa, del otoronco como tigre, de las varias pronunciaciones de guaca, etc.). Sin embargo, se atribuye a sí mismo siempre (indebidamente, a veces) la autoridad para identificar el léxico correcto, sin mencionar glosario anterior alguno: de haber reconocido ante el lector su dependencia personal de un diccionario jesuita ajeno, tal vez su autoridad testimonial se hubiera resentido, al menos desde un punto de vista retórico. Es decir, se hubiera visto menos reforzada la credibilidad del lector respecto de su crítica al testimonio ajeno, en gran parte fundada en la supuesta impropiedad de la lengua quechua usada por la fuente criticada.

Sin embargo, la estrecha dependencia suya respecto del Arte y vocabulario es tan clara que podemos confirmar - a veces, corregir- algunas de sus definiciones o pronunciaciones, gracias a una simple consulta del mismo (por ejemplo, el caso tan citado de sacharuna como 'montañés', en el cap. 31 del libro IX sobre "Nombres nuevos para nombrar diversas generaciones", es confundida con sallcaruna, según el Arte y Vocabulario). Todos los casos que he hallado, en que corrige pronunciaciones ajenas, se basan en el Arte y Vocabulario: por ello merece la pena considerar el uso de la autoridad ajena por el Inca en estos 37 capítulos de historia natural, en los que vuelve a producirse la paradoja de su dependencia directa de testimonios ajenos, al mismo tiempo (justamente) que se produce el 'reforzamiento' de su propio testimonio. Incluso cuando refiere anécdotas que parecen propias, se trata en muchos casos de lecturas ajenas, asumidas tan magistralmente como propias que el lector no duda en concederles el crédito testimonial demandado. Literariamente tiene alguna particularidad que merece destacarse: referirse a los hechos narrados como parte de su propia vida, incluso preferentemente de su infancia. Luego, cabe tener en cuenta escenas públicas en que 'deja su huella' de testigo, como cuando describe las escenas frecuentes de caballeros que ofrecen convites, cenas, premios..., en los que el autor se hallaba presente, o conocía al testigo citado. Hay momentos de verdadero lirismo, especialmente cuando se describe a sí mismo como 'actor' perjudicado en el reparto de bienes (las uvas, los espárragos). Y especialmente aquellos en que salen a flor las sorpresas indianas ante lo hispano, y las melancolías hispanas por los productos viejos, nuevamente recuperados. Abordemos textualmente alguna de estas diferentes escenas.

Primeramente, en cuanto al establecimiento de papeles concedido en su texto a cada fuente usada para noticias naturalistas, cabe referirse a una especie de casting de autores y obras, en que nombra a sus informantes principales (a los que cita literal y repetidamente: especialmente a los dos conocidos jesuitas peruanistas Blas Valera y Jose de Acosta). Del primero es innecesario remarcar su trascendencia intertextual, ya que solo conocemos la obra de Valera a través de estas citas literales del Inca. Respecto de la segunda fuente hay sobre todo cuatro ocasiones en que se le cita o usa particularmente: al hablar de las recuas de llamas (VIII, 16), al hacerlo 
de las monas (VIII, 18), luego hablando de las perlas (VIII, 23), y finalmente, de las hortalizas (IX, 29).

En el primero de los casos no hay cita literal, aunque aparece dos veces su nombre, para autorizarse: "El padre Joseph de Acosta (libro IV, cap. 41) dice mucho en loor de este ganado mayor y de sus provechos" (VIII, 16). Puede seguirse, sin embargo, mucho de este capítulo 41 citado para entender las detalladas explicaciones del Inca, hasta incluso poder corregir el texto de Lisboa de algún error ("Entre los indios llevan a cargo 25 carneros para cargar y descargar": por 'carnereros'). Es muy evidente la familiaridad del inca con el mundo de los arrieros andinos en este cap. 16, que aparece muchas otras veces en su libro, revelando su intensa dedicación al negocio del comercio de bienes agrarios, antes y después de su venida a Córdoba. Basta para mostrarlo una referencia, como botón de muestra, sobre el transporte de mercancías:

Tiene el pescuezo largo y parejo, cuyo pellejo desollaban los indios cerrado, y lo sobaban con sebo hasta ablandarlo y ponerlo como curtido, y de ello hacían las suelas del calzado que traían... Demás desto sirve aquel ganado a indios y a españoles de llevarles sus mercaderías dondequiera que las quieren llevar ... El peso que lleva es de tres a cuatro arrobas; las jornadas que caminan son de a tres leguas, porque no es ganado de mucho trabajo; no le han de sacar de su paso porque se cansa... Para que no lleguen a cansarse llevan en las recuas 40 o 50 carneros vacíos y, en sintiendo enflaquecer alguno con la carga, se la quitan luego y la pasan a otro, antes que se eche: porque, en echándose, no hay otro remedio sino matarlo.... Albarda ni otro aparejo alguno no lo han menester, porque tienen lana gruesa bastante para sufrir la carga que les echan, y los trajineros tienen cuidado de acomodar y juntar los tercios de un lado y de otro, de manera que la sobrecarga no toque en el espinazo, que es donde le podría matar. Los tercios no van asidos con el cordel que los arrieros llaman 'lazo' porque, no llevando el carnero jalma ni albarda, podría entrársele el cordel en las carnes, con el peso de la carga. Los tercios van cosidos uno con otro por las arpilleras y, aunque las costuras asienten sobre el espinazo, no les hace mal, como no llegue la sobrecarga. Entre los indios llevan a cargo 25 carne[re]ros [ver Acosta IV, 41] para cargar y descargar, por ayudarse el uno al otro: que uno solo no podría valerse, yendo los tercios juntos, como se ha dicho... Todo lo que hemos dicho pasaba en mi tiempo, que yo lo vi por mis ojos, no sé ahora cómo pasa; traté con muchos de los que iban y venían.

La otra ocasión en que cita más largamente al P. Acosta es hablando de las monas y de sus habilidades, a lo que agrega cosas de su cosecha ("Hasta aquí es del P. Acosta: donde pudiera añadir [otras varias cosas]... pero de micos y monas baste", VIII, 18). Llega a discutir con el mismo autor el nombre del tigre y del oso, aunque se queje de su poca memoria de haberlo olvidado por causa de los 42 años transcurridos en que falta de su tierra (1560-1602). Todavía más larga es la citación del mismo autor en el cap. 23 (libro VIII, "De las esmeraldas, turquesas y perlas"), 
en que llega a proponer una corrección al texto original de Sevilla ('sácanse' por 'lábranse'), y agrega varias experiencias propias sobre perlas extraordinarias como la llegada a Sevilla en 1579 de la más famosa, llamada 'la peregrina', destinada a Felipe II, que exhibió en nuestros días la actriz Liz Taylor en su película sobre Ana Bolena (Anne of the Thousand Days, "Ana, la de los mil días"), como regalo de su marido R. Burton. A lo que comenta el autor: "Para ver la gran riqueza de este monarca, es bien leer aquel libro IV y todos los demás del P. Acosta, donde se verán tantas cosas y tan grandes como las que se han descubierto en el Nuevo Mundo" (VIII, 23). Finalmente depende también del jesuita castellano para hablar de las hortalizas americanas, "cuya autoridad refuerza mi ánimo..." (IX, 29). A lo cual agrega la famosa anécdota de los melones, comidos secretamente por los porteadores andinos y denunciados públicamente por una carta escrita por el remitente al destinatario, llevada junto con los melones. Anécdota que el Inca reconoce deber asimismo a Gómara, quien lo cuenta como caso ocurrido en Cuba.

Todo el rato hallamos al Inca luchando contra la desmemoria, producida por la lejanía y el paso del tiempo, y es por ello que establece un diálogo con esa facultad humana deficiente, que replica ante su queja:

Hay otra fruta muy buena, que los españoles llaman 'pepino' porque se le parece algo en el talle... El nombre que los indios les dan se me ha ido de la memoria; aunque, fatigándola yo en este paso muchas veces y muchos días, y reprendiéndola por la mala guarda que ha hecho y hace de muchos vocablos de nuestro lenguaje, me ofreció - por disculparse- este nombre: cacham, por pepino. No sé si me engaña, confiada de que por la distancia del lugar y ausencia de los míos no podré averiguar tan aína el engaño. Mis parientes, los indios y mestizos del Cozco y todo el Perú, serán jueces de esta mi ignorancia y de otras muchas que hallarán en esta mi obra; perdónenmelas, pues soy suyo y que sólo por servirles tomé un trabajo tan incomportable como esto lo es para mis pocas fuerzas (sin ninguna esperanza de galardón suyo ni ajeno)" (VIII, 11)

Tal vez quiere dejar intacta su autoridad de hablante puro, que se fía del todo de sus recuerdos. Otra ocasión se da de desmemoria auto-denunciada, en el caso de del tigre, en que discute con el P. Acosta:

Cómo se llame el tigre en la lengua general del Perú, se me ha olvidado, con ser nombre del animal más fiero que hay en mi tierra. Reprendiendo yo mi memoria por estos descuidos, me responde que por qué le riño de lo que yo mismo tengo la culpa; que advierta yo que ha cuarenta y dos años que no hablo ni leo en aquella lengua. Válgame este descargo para el que quisiere culparme de haber olvidado mi lenguaje. Creo que el tigre se llama uturuncu, aunque el padre maestro Acosta da este nombre al oso, diciendo otoroncos, conforme a la 
corru[p]tela española; no sé cuál de los dos se engaña; creo que Su Paternidad (VIII, 18). ${ }^{12}$

No se entiende que no recurra en estos casos al Arte y Vocabulario, publicado en 1586 a partir de los lingüistas colaboradores del concilio limense, porque sus soluciones se parecen justamente al léxico quechua ya codificado (otoronco y cachun vienen recogidos, como muchos otros que usa el Inca). En todo caso, es la autoridad de su experiencia personal la que valora primeramente, como deja saber en el cap. 22 del libro VIII, dedicado a los ríos famosos del Perú. Aquí, alertado por su propia experiencia del viaje de venida a España (en que fue preguntando a cada paso novedades, como hiciera asimismo el $\mathrm{P}$. Acosta, 27 años después que él), se dio cuenta de la importancia de tener en cuenta las experiencias anteriores, sin fiarse de opiniones varias, y así lo hace constar hablando de uno de los cuatro ríos famosos (Magdalena, Orellana u Orinoco, Amazonas o Marañón, y Río de la Plata):

El 'de Orellana', que le llamamos así a diferencia del río Marañón, tiene -según la misma carta- 54 leguas de boca, antes más que menos; y, aunque algunos autores le dan 30 leguas de boca y otros menos, y otros 40 y otros 70, me pareció poner la opinión de los mareantes. Que no es opinión sino experiencia, porque a aquella república que anda sobre aguas de la mar le conviene no fiarse de opiniones, sino traer en las manos la verdad sacada en limpio (VIII, 22)

\section{Garcilaso, hombre experimentado}

Creo que donde puede considerársele un verdadero experto en historia natural es en lo que tiene que ver con el caballo, en lo que es famosa su dedicación antes y después de su venida a España. Aurelio Miró Quesada le dedicó un capítulo en su estudio biográfico de 1971 a "El Inca Garcilaso y los caballos" (original de 1964), donde se recogen detalles de su afición desde su juventud cuzqueña hasta su estancia en Montilla, aparte la valoración del mismo que hace en el proceso de la conquista americana, señalando las muchas veces que salen los caballos en sus tres obras americanas, especialmente en la segunda parte de los Comentarios. Aparte lo que nos habla en sus Comentarios, es conocida hoy en Montilla su afición personal y sus habilidades en la doma, que le ganaron un premio local en 1579: lo testimonia asimismo la amplia dedicación a espacio de cuadras en casa de su tío. Nosotros lo hemos observado con más detalle en la primera parte de sus Comentarios, donde le

${ }^{12}$ Creo que el Inca establece en estos dos casos un diálogo cervantino con su propia memoria, cuando crea personajes ficticios para establecer un diálogo jugoso con ellos, que favorezca una escena convincente. Me refiero al largo capítulo del retablo de Maese Pedro (caps. 25-26 de la segunda parte), en el que se da voz directa o indirecta a varias docenas de personajes. 
dedica el largo capítulo 16 del último libro (primero de los que tratan "las cosas que los castellanos han llevado al Perú, que no había antes de ellos").

En este apartado se hace historia de la llegada del caballo andaluz al Nuevo Mundo, primero en las Antillas y luego en Tierra Firme: donde es conocido que se extendieron ampliamente por las praderas de Norteamérica (caracterizando al indio de los 'películas del Oeste', cuya transformación cultural por causa del caballo ha sido muy estudiada por los antropólogos), y en la pampa sudamericana y Chile, donde hicieron el mismo efecto transformador sobre el aborigen, y fueron objeto de estudio atento por naturalistas conocidos como el ilustrado Feliz de Azara. El Inca Garcilaso conoce que la primera difusión rápida tuvo que ver con su uso en la conquista: lo que comenzó a languidecer a partir de los 70, con el control de la administración filipina sobre la hueste conquistadora. Ahora, el negocio de criar caballos ha pasado al ganado vacuno, pero el Inca demuestra su interés personal, mostrando detenidamente cómo se capturaban los caballos salvajes y los domaban en dos o tres semanas. Es decir, en mucho menos tiempo que en España: por eso es que propone 're-animar' el negocio caballar con la importación española de caballos domados en América, y especialmente en el Perú:

Muchas veces, imaginando lo mucho que valen los buenos caballos en España, y cuán buenos son los de aquellas islas de talle, obra y colores, me admiro de que no los traigan de allí, siquiera en reconocimiento del beneficio que España les hizo en enviárselos; pues, para traerlos de la isla de Cuba, tienen lo más del camino andado y los navíos por la mayor parte vienen vacíos; los caballos del Perú se hacen más temprano que los de España, que la primera vez que jugué cañas en el Cozco fue en un caballo tan nuevo que aún no había cumplido tres años.

Me ha parecido que su interés por el mundo del caballo es tal que llega a definir su propia identidad oscilante de 'español', hasta el punto que habla del miedo indio al caballo de un modo que uno llega a dudar si alguna vez se sintió indio (a pesar de sus declaraciones en ese sentido):

Comúnmente los indios tienen grandísimo miedo a los caballos; en viéndolos correr se desatinan de tal manera que, por ancha que sea la calle, no saben arrimarse a una de las paredes y dejarle pasar, sino que les parece que dondequiera que estén (como sea en el suelo) los han de trompillar [...] En ninguna manera les parecía que estaban seguros, si no era teniendo algún español delante, y aun no se daban por asegurados del todo; cierto no se puede encarecer lo que en esto había en mis tiempos. Ya ahora por la mucha comunicación es menos el miedo, pero no tanto que indio alguno se haya atrevido a ser herrador; $y$, aunque en los demás oficios que de los españoles han aprendido hay muy grandes oficiales, no han querido enseñarse a herrar por no tratar los caballos de tan cerca; $\mathrm{y}$, aunque es verdad que en aquellos tiempos había muchos indios criados de 
españoles que almohazaban y curaban los caballos, mas no osaban subir en ellos. Digo verdad, que yo no vi indio alguno a caballo; [...]; dícenme que ya ahora hay algunos indios que se atreven a herrar caballos, mas que son muy pocos" (IX, 16)

Este mundo desbrozado del caballo le sirve no solamente para hablar de este campo limitado, sino para describir por comparación otros mundos de la fauna americana, incluso la nativa: así para describir los colores de los guanacos, su modo de defenderse entre machos y hembras y de gemir (VIII; 16), la velocidad comparada de los avestruces, (VIII, 20), etc. Por otro lado, el caballo definía no solamente al hombre español frente al indio, sino a la aristocracia frente a la plebe, y a todo su aparato honorífico y de distinciones. Creo que puede decirse incluso que, a juicio de Garcilaso, el caballo conlleva un signo de superioridad cultural de Occidente con el mundo andino:

Por cualquiera ventaja que los españoles hacían a los indios (como correr caballos, domar novillos y romper la tierra con ellos, hacer molinos y arcos de puente en ríos grandes, tirar con un arcabuz y matar con él a 100 y 200 pasos, y otras cosas semejantes), todas las atribuían a divinidad; y por ende les llamaron dioses, como lo causó la carta [que informaba de los melones enviados y comidos, y notados a faltar por una carta adjunta, que los indios no supieron que hablaba por sí sola] $(1609, \mathrm{IV}, 29)$.

Es muy posible que el servicio militar que cumplió Garcilaso en la guerra de las Alpujarras de 1568-70 (por el que obtuvo tres distinciones como capitán, aunque ningún premio: a juzgar por sus quejas de la ingratitud real) no se deban a acciones de guerra, sino a levas de soldados en la comarca de Montilla, a las órdenes del marqués de Priego, y sobre todo a servicios relacionados con el caballo, incluyendo enormes gastos personales. Si bien su conocimiento del mismo es considerable y de primera mano, todo lo que tiene que ver en sus obras con la guerra da la impresión de ser mero relato 'desde la barrera' (adoptando el lenguaje taurino). Tras tantas descripciones de acciones caballerescas en la historia de la Florida y del Perú (donde no sólo son caballeros los cristianos, sino sobre todo los incas: que parecen 'caballeros andantes', deshacedores de entuertos, más que conquistadores militares propiamente dichos: aun así en desventaja, por estar sin caballos ni escritura), sería extraño que su autor hubiera practicado la guerra de conquista. ${ }^{13} \mathrm{~A}$ veces, la ética caballeresca con que quiere describir a los incas se deja contaminar de un espíritu del que, con cierto pudor, se declara 'descontaminado': de las novelas de caballería que el Quijote quiso ridiculizar (aunque parece que para ensalzar, como el propio Inca, una moral en trance de pérdida en su tiempo). Véase cómo describe la

${ }^{13}$ La misma duda asalta a su biógrafo John G. Varner, op. cit., cap. 11. 
educación rigurosa de los incas para 'armarse caballeros', reconocidos como tal sin embarazo alguno:

Este nombre huaracu es de la lengua general del Perú: suena tanto como en castellano "armar caballero", porque era dar insignias de varón a los mozos de la sangre real y habilitarlos, así para ir a la guerra como para tomar estado. Sin las cuales insignias no eran capaces ni para lo uno ni para lo otro: que, como dicen los libros de caballerías, eran donceles que no podían vestir armas" (VI, 24, "Armaban caballeros a los incas, y cómo los examinaban").

Por otro lado, el énfasis del autor en el libro IX sobre los animales importados de España consiste generalmente más en su explotación y precio de venta (en su 'granjería', dicho en su lenguaje) que en su uso diario y su cultivo. Así ocurre con las vacas, cabras, cerdos, asnos, camellos, ovejas, conejos, gallinas, etc. Aunque, a veces se echa de ver su conocimiento íntimo de su manejo: donde aparece éste más claramente es en la descripción de las plantas importadas, que trata después de la fauna, y en orden de importancia económica (trigo, uvas, olivo, azúcar, hortalizas, lino...). A la vid le dedica dos capítulos (IX, 25 y 26), equivalentes a la longitud mayor dedicada a los caballos, en el caso de la fauna preferida. Describe primero las variedades de uva llevadas (casi todas dando vino tinto o clarete -es decir 'aloque'- no blanco). Se refiere asimismo al premio establecido por los RR.CC. para estimular la siembra de productos agrícolas de primera necesidad (trigo, uvas), a las costumbres de uso de vino en las comidas, a su precio creciente al principio, etc.

Quiero destacar especialmente la conciencia despierta en nuestro autor de los cambios de valor y precio de los alimentos o productos propios, y en particular de los españoles cuando carecían de ellos, al principio. Así, hablando de los cerdos y su precio excesivo (1600 pesos por una pareja, o 100 por cada lechón en el vientre de la madre, información tomada del cronista Cieza), reflexiona el Inca:

Estos excesos y otros semejantes han hecho los españoles con el amor de su patria en el Nuevo Mundo, en sus principios: que, como fuesen cosas llevadas de España, no paraban en el precio para las comprar y criar, que les parescía que no podían vivir sin ellas (IX, 19).

Y poco después, hablando de la biznaga y el anís recién reproducido en el Cuzco, y recibidos por los españoles como complementos culinarios imprescindibles, recalca este fenómeno del sobreprecio debido a la escasez originaria:

También salió por este tiempo el anís en el Cozco, el cual se echaba en el pan por cosa de mucha estima, como si fuera el néctar o la ambrosía de los poetas. Desta manera se estimaron todas las cosas de España a los principios, cuando se 
empezaron a dar en el Perú: y escríbense, aunque son de poca importancia, porque en los tiempos venideros -que es cuando más sirven las historias- quizá holgarán saber estos principios.

El autor se hace eco de la productividad inesperada en plantas y animales del Viejo Mundo en el Nuevo, de las maravillas naturales sucedidas con plantas procedentes del Viejo (sobre todo al principo), pero también de su valor y precio cambiante, dada su indudable sensibilidad económica. Todo el rato nos ofrece los cambios de precio de las cosas, a medida que son más abundantes, en lo que muestra haber percibido los principios de la ciencia económica, que se reconoce hoy a la escuela de Salamanca, y en particular a su fuente peruana, el cronista jesuita José de Acosta. Como éste, ofrece multitud de precios oscilantes de los productos, e incluso menciona el término 'precio' en 4 de los títulos de los 33 capítulos naturalistas: "De las yeguas y caballos, y cómo los criaban al principio, y lo mucho que valian" (IX, 16), "De las vacas y bueyes, y sus precios altos y bajos" (IX, 17), "De los camellos, asnos y cabras, y sus precios y mucha cría" (IX, 18), "Del vino y del primero que hizo vino en el Cozco, y de sus precios" (IX, 26). Como muestra, un botón referido a las vacas:

Cuando las vacas empezaron a venderse, valían a 200 pesos; fueron bajando poco a poco como iban multiplicando, y después bajaron de golpe a lo que hoy valen [da los precios de 100 pesos en 1554, 17 pesos en 1559]... . Del año de 1590 acá, me escriben del Perú que valen las vacas en el Cozco a 6 y a 7 ducados, compradas una o dos; pero compradas en junto valen a menos (IX, 17).

Pero más relevante es su percepción de que los precios derivan de muchos factores (existencia natural del producto, ausencia de producto sustitutorio, distancia del mercado, modo de transporte, gustos del mercado...), pero asimismo de la cantidad de capital circulante, lo que afectaba especialmente a un país como Perú productor de oro y plata. Véase una muestra interesante:

Las minas prometen tanta riqueza que, a pocos años que se labren, valdrá más el hierro que la plata. Este pronóstico vi yo cumplido los años de 1554 y 55 , que en la guerra de Francisco Hernández Girón valió una herradura de caballo 5 pesos, que son 6 ducados, y una de mula 4 pesos; dos clavos de herrar, un tomín, que son 56 maravedís... Causó esta carestía aquella guerra, porque en dos años que duró no pasaron armadas al Perú, que llevan las cosas de España. También la causó la mucha plata que daban las minas, que tres y cuatro años antes de los que hemos nombrado, llegó a valer un cesto de la hierba que llaman 'cuca' 36 ducados, y una hanega de trigo 24 ó 25 ducados; lo mismo valió el maíz, y al respecto el vestir y calzar, y el vino: que las primeras botijas, hasta que hubo abundancia, se vendían a 200 y a más ducados. Y, con ser la tierra tan rica y abundante de oro y plata y piedras preciosas, como todo el mundo sabe, los 
naturales de ella son la gente más pobre y mísera que hay en el universo (VIII, 24)

Con lo cual nos termina advirtiendo la conocida 'ley económica' de la utilidad marginal decreciente, a medida de su aumento descontrolado y, sobre todo, a partir del aumento de la masa dineraria, que hace subir los precios sin control posible. De algún modo, aunque la historia natural no era una materia que le interesaba originalmente, no cabe duda que nuestro autor ha sabido sacarle partido al tema para describir el mundo de los incas frente al español del Perú, la diferente curiosidad de cada uno por los productos el otro, mostrando a veces una sabia 'simbolización' de las emociones características de cada uno, los contrastes en habilidades y saberes, los cambios de valoración de un mismo producto en uno de ellos.

Ello, sin aludir a las contínuas muestras de buena literatura en la descripción de estos seres naturales y de su uso por parte de cada uno de los dos grupos humanos, a lo largo del tiempo. Para ello, como hemos visto, se vale de sus variadas lecturas y coloquios sostenidos a lo largo de su vida, pero añade a todo ello un cierto orden propio. Para empezar, la muestra que nos ofrece de la naturaleza andina se compone de productos nuevos y viejos, propios y ajenos, algunos compartidos y otros exclusivos de uno de esos dos mundos. Algunos de ellos son descritos como aparecen en principio, en su prístina apariencia, y otros como se desarrollan a medida que los hombres lo van conociendo y usando. Dentro de los productos naturales o importados del Viejo Mundo, percibimos una gradación de productos, desde la fauna a las plantas y finalmente a los productos metálicos. Incluso, como último capítulo, se nos ofrece una somera descripción de la propia naturaleza humana, señalando la diversidad de razas surgidas del encuentro de blancos, negros e indios (salvaje, criollo, mulato, cholo, mestizo, con sus diferentes grados: cuatralbo, tresalbo...), donde el autor vuelve a aprovechar la ocasión para definirse a sí mismo como 'mestizo' ("me lo llamo yo a boca llena, y me honro con él"), analizando los sentidos negativos y positivos en que puede tomarse el término.

Lo mejor que puede decirse de estos capítulos es que su autor parece tener una delicada 'conciencia del paisaje', dentro del cual se desarrolla la acción histórica que relata. No sólo nos describe los accidentes de su Cuzco natal, con sus calles y casas minuciosamente recordadas, o los diferentes templos prehispánicos (Coricancha, Pachacámac y Copacabana) sino que parece haber recorrido el Perú entero, a su paso para España, y es entonces que distingue paisajes diferentes: distingue las zonas cultivadas (campos de coca, maíz y papas, de piñas, uvas, olivos y espárragos, etc., algunas en andenerías laboriosamente construidas) de las naturales (costas del Callao o Panamá, valle de Yucay, de Ica, de Lima, etc.). Solamente mencionaré dos escenas (para terminar), una en tierra y otra en el mar, que me han parecido prueban bien su sensibilidad ante la vida natural, descrita como llena de tanto dramatismo de fondo y poesía de forma como la población 
humana. En el primer caso observó la persecución entre dos tipos de pájaros, y admira cómo supo defenderse el más débil:

En el llano de Yucay vi volar dos cernícalos a un pajarillo, traíanlo de lejos; encerróseles en un árbol grande y espeso que hay en aquel llano (yo lo dejé en pie, que los indios en su gentilidad tenían por sagrado, porque sus reyes se ponían debajo de él a ver las fiestas que en aquel hermoso llano se hacían). El uno de los cernícalos, usando de su natural industria, entró por el árbol a echar fuera al pajarillo; el otro se subió en el aire, encima del árbol, para ver por dónde salía, y, en saliendo el pájaro, forzado del que lo perseguía, cayó a él como un neblí. El pajarillo volvió a socorrerse en el árbol; el cernícalo que cayó a él entró a echarle fuera, y el que le había sacado del árbol se subió en el aire, como hizo el primero, para ver por dónde salía. De esta manera los cernícalos, trocándose ya el uno ya el otro, entraron y salieron del árbol cuatro veces, y otras tantas se les encerró el pajarillo con grande ánimo, defendiendo su vida: hasta que la quinta vez se les fue al río y, en unos paredones de edificios antiguos que por aquella banda había, se les escapó. Con gran contento y gusto de cuatro o cinco españoles que habían estado mirando la volatería, admirados de lo que la naturaleza enseña a todas sus criaturas, hasta las aves tan pequeñas, para sustentar sus vidas: unas acometiendo y otras huyendo, con tanta industria y maña como se ve a cada paso (VIII, 20).

En cuanto al segundo caso, no se trata del valle fértil de Yucay, sino de una escena observada en pleno viaje marino, seguramente de venida a España:

[...] hay otras aves marinas que los españoles llaman 'alcatraces': son poco menores que las avutardas. Mantiénense de pescado, es cosa de mucho gusto ver cómo pescan. A ciertas horas del día, por la mañana y por la tarde - debe de ser a las horas que el pescado se levanta a sobreaguarse, o cuando las aves tienen más hambre-, ellas se ponen muchas juntas como dos torres en alto; y de allí como halcones de altanería, las alas cerradas, se dejan caer a coger el pescado y se za[m]bullen y entran debajo del agua, que parece que se han ahogado; debe ser por huirles mucho el pescado. Y cuando más se certifica la sospecha, las ven salir con el pez atravesado en la boca y, volando en el aire, lo engullen. Es gusto ver caer unas y oír los golpazos que dan en el agua; y, al mismo tiempo, ver salir otras con la presa hecha; y ver otras que, a medio caer, se vuelven a levantar y subir en alto, por desconfiar del lance. En suma, es ver doscientos halcones juntos en altanería que bajan y suban a veces, como los martillos del herrero.

No hace falta ponderar en ninguno de los dos casos la belleza de las imágenes evocadas ni la sensibilidad del autor, pues su texto habla elocuentemente. En ambos se trata, así lo sentimos, de escenas tomadas de su propia experiencia, que el autor nos permite compartir en primer plano gracias tanto a su curiosidad natural como a su dominio del lenguaje. 